\title{
Surtos de toxoplasmose em seres humanos e animais
}

\section{Outbreaks of toxoplasmosis in human beings and animal}

\author{
Rafael André Ferreira Dias ${ }^{1}$; Roberta Lemos Freire ${ }^{2 *}$
}

\section{Resumo}

\begin{abstract}
A toxoplasmose é uma zoonoses de distribuição mundial e acomete animais de sangue quente das mais variadas espécies. Os surtos de toxoplasmose em seres humanos e animais freqüentemente não são relatados. Isto ocorre, possivelmente, em função desta infecção caracterizar-se por sintomas ausentes ou brandos tanto em humanos quanto em animais. Desta maneira, existem dificuldades na caracterização clínica desta patologia com confirmação laboratorial e posterior notificação. Esta revisão enfatiza os surtos de toxoplasmose notificados em humanos e animais, suas fontes de infecção e vias de transmissão que variam de acordo com os hábitos locais e as condições sanitárias de cada região. Aborda ainda a caracterização genética de cepas de Toxoplasma gondii e métodos de prevenção.
\end{abstract}

Palavras-chave: Toxoplasma gondii, surto, cepas, prevenção

\begin{abstract}
Toxoplasmosis is one of the biggest wild world zoonosis and it can attack blood warmed animals from many species. Outbreaks of toxoplasmosis in humans and animals are not related frequently and it could be due to either weak or asymptomatic characteristics. So, there are difficulties in the clinical characterization of this pathology with laboratorial confirmation and posterior notification. This review emphasizes the informed outbreaks in humans and animals, its sources of infection and ways of transmission that vary in accordance with local habits and sanitary conditions. It still approaches the genetic characterization of Toxoplasma gondii strains and prevention methods.
\end{abstract}

keywords: Toxoplasma gondii, outbreak, strain, prevention

\section{Introdução}

A toxoplasmose, zoonose causada pelo protozoário Toxoplasma gondii, tem distribuição mundial e acomete animais de sangue quente (JACOBS; LUNDE, 1957). Os felídeos, silvestres ou domésticos, são os hospedeiros definitivos e neles o parasita realiza a multiplicação enteroepitelial que culmina com a produção e eliminação de oocistos pelas fezes que contaminam o meio ambiente (DUBEY, 1977). As fezes de um gato doméstico podem conter em torno de 10 milhões de oocistos em pico de eliminação. No meio ambiente estes oocistos tornam-se infectantes após um período de um a cinco dias, dependendo das condições de umidade e temperatura (DUBEY; BEATIE, 1988). Devido a sua resistência aos agentes químicos e físicos, os oocistos mantêm-se viáveis durante meses ou anos (FRENKEL, 1990).

O homem adquire a infecção toxoplasmica tanto pela ingestão de oocistos esporulados e cistos teciduais em carne crua ou mal cozida, como

\footnotetext{
1 Médico Veterinário e Mestre pelo Programa de Pos-Graduaçao em Ciencia Animal, Sanidade Animal, DMVP, UEL, Paraná, Brasil

2 Docente do Departamento de Medicina Veterinaria Preventiva, CCA, DMVP, UEL, Paraná, Brasil, CP 6001, CEP 86051-990, Londrina, Parana, Brasil. e-mail: rlfreire@uel.br.

* Autor para correspondência.
} 
congenitamente pela via transplacentária (DUBEY; TOWLE, 1986; FRENKEL, 1990). A incidência de infecção pré-natal pode variar de 1 a 120 em 10.000 nascimentos, sendo que a soroprevalência entre mulheres em idade fértil pode variar de 4 a $85 \%$ (TENTER et al., 2000). Estima-se um custo anual acima de cinco milhões de dólares com tratamentos de crianças congenitamente infectadas nos Estados Unidos (FRENKEL, 1990; GUERINA et al., 1994). Nos seres humanos a infecção pelo $T$. gondii é na maioria das vezes assintomática, os sinais clínicos ocorrem com maior feqüência em imunocomprometidos, como os portadores do HIV, em pessoas com toxoplasmose ocular e em crianças congênitamente infectadas (DUBEY, 1996). No Brasil, a região de Erechim-RS é uma área na qual a toxoplasmose ocular apresenta-se endêmica, Silveira (2002) estudou 215 moradores da região e encontrou $17,7 \%$ de lesões compatíveis com a toxoplasmose ocular.

\section{Contaminação de alimentos de origem animal e da água}

A infecção pela via oral é a principal forma de ocorrência e disseminação do agente para a população humana e animal (DUBEY; TOWLE, 1986). Produtos cárneos oriundos das espécies suína, ovina e caprina, contendo cistos teciduais, são uma das principais vias de transmissão para a população humana. Em estudos realizados nos Estados Unidos, Austrália e Europa, o parasita não foi isolado em carnes bovinas, nesta espécie animal os cistos teciduais parecem ter menor viabilidade e são raramente encontrados (DUBEY; BEATIE, 1988).

Vários estudos soroepidemiológicos da toxoplasmose em suínos foram realizados em diferentes países; Dubey et al. (1991) encontraram, nos Estados Unidos, uma taxa de 23\% em 11.229 animais com menos de sete meses de idade destinados ao consumo e de 41,4\% em 613 suínos adultos. Montoya et al. (1981) detectaram 30\% de suínos soropositivos na Colômbia, Suaréz-Aranda et al. (2000) encontraram, em um levantamento realizado no Peru, uma prevalência de $32,3 \%$ em suínos provenientes de granjas.

Em estudos realizados no Brasil, Araújo; Souza (1996) colheram 274 amostras de sangue de suínos em abatedouros da região de Erechim (RS) e verificaram que $7,3 \%$ dos animais foram sororeagentes ao $T$. gondii pela Imunofluorêscencia Indireta (IFI). Em animais de abatedouros do Estado de São Paulo Suaréz-Aranda et al. (2000) obtiveram resultados semelhantes, uma vez que a taxa de sororeagentes foi de 9,6\%. Entretanto, na região metropolitana de Recife (PE) o perfil de ocorrência da toxoplasmose nos suínos se alterou, provavelmente devido às diferenças de manejo e à faixa etária pesquisada; $54,12 \%$ de 170 amostras de sangue colhidas de fêmeas pluríparas foram positivas (PORTO et al., 1999).

No Paraná estudos realizados em granjas da região de Londrina revelaram a taxa de $37,84 \%$ de soro-reagentes ao $T$. gondii em 1.131 suínos (VIDOTTO et al. 1990); após 10 anos esta taxa diminuiu para 15,35\% em 521 animais avaliados (TSUTSUI, 2000). Navarro et al. (1992) encontraram 31 amostras de carne e cérebro de suínos positivas ao bioensaio em camundongos, do total de 171 oriundas de açougues da cidade de Londrina, revelando a presença de cistos viáveis de T. gondii.

A alta produção e consumo de carne suína, a elevada disseminação e prevalência do $T$. gondii, associada ao fato de que os cistos podem permanecer viáveis na musculatura dos suínos infectados por mais de 171 dias (DUBEY; MURREL; FAYER, 1984) e de não serem detectáveis ao abate (KOSKI, 1990); torna este alimento, quando ingerido cru ou mal cozido, uma importante via de transmissão da toxoplasmose ao homem.

A água também pode ser uma via de transmissão para a toxoplasmose, atuando como um disseminador de oocistos para a população que venha a utilizá-la. A contaminação de reservatórios municipais de água, 
por fezes de felinos infectados e eliminando oocistos de $T$. gondii, pode levar a surtos ou epidemias, envolvendo uma cidade ou mesmo uma região (FUNASA, 2002).

\section{Tipos de cepa}

Vários fatores, como o estado imunológico do hospedeiro, a virulência da cepa, o número de parasitas infectantes e a rota de infecção, atuam na manifestação de sinais clínicos, quando da ocorrência da toxoplasmose (DEROUIN, 1992).

As amostras de T. gondii isoladas em diferentes espécies animais, apesar de morfologicamente indistinguíveis, variam quanto a sua virulência e patogenicidade (DUBEY; FRENKEL, 1973). Tais amostras têm sido, a princípio, diferenciadas com base na virulência estabelecida através da morbidade e mortalidade em camundongos Suíços albinos (MITSUKA-BREGANÓ et al. 1998). Esta diferença definida em camundongos não reflete, necessariamente, a virulência em outros hospedeiros, mas foi adotada como modelo para caracterizar o parasita sob este aspecto. Atualmente, adotando-se métodos de caracterização molecular, evidenciou-se a existência de linhagens bem definidas dentro da espécie $T$. gondi,i designadas como tipo I, II, III (DARDÉ; BOUTEILLE; PRESTE-ALEXANDRE, 1988; DARDÉ, 1996; HOWE; SIBLEY 1995).

Cepas tipo I ou recombinantes do tipo I e III parecem resultar na toxoplasmose clínica, porém o isolamento e a caracterização genética têm sido restritos essencialmente a pacientes doentes com toxoplasmose (HOWE et al., 1997; GRIGG et al., 2001; FUENTES et al., 2001). Cepas isoladas de animais, independente da condição clínica, são predominantemente caracterizadas em tipo II ou III (HOWE; SIBLEY, 1995; MONDRAGON et al., 1998). No entanto, estudos realizados em várias partes do mundo em galinhas de vida livre, consideradas indicadores da prevalência do T. gondii no ambiente pelo fato de ciscarem, têm revelado a ausência do tipo II nesta espécie animal, em algumas localidades (Tabela 1).

Tabela 1- Tipos genéticos de cepas de Toxoplasma gondii isoladas de galinhas de vida livre em diferentes países.

\begin{tabular}{ccccccc}
\hline Localidade & $\mathbf{n}^{\circ}$ isolados & Tipo I & Tipo II & Tipo III & Tipo I + III & Referências \\
\hline Argentina & 9 & 1 & 1 & 7 & 0 & Dubey et al. $(2003 \mathrm{a})$ \\
Egito & 20 & 0 & 3 & 17 & 0 & Dubey et al. $(2003 \mathrm{~b})$ \\
EUA & 19 & 0 & 5 & 14 & 0 & Dubey et al. $(2003 \mathrm{c})$ \\
Brasil (SP) & 25 & 16 & 0 & 9 & 0 & Dubey et al. (2002) \\
Brasil (RJ) & 48 & 34 & 0 & 13 & 1 & Dubey et al. $(2003 \mathrm{~d})$ \\
Brasil (PR) & 13 & 7 & 0 & 6 & 0 & Dubey et al. (2003e) \\
\hline
\end{tabular}

Em estudo realizado em 58 gatos domésticos do município de Santa Isabel do Ivaí - Pr, Brasil, onde recentemente havia ocorrido um surto de toxoplasmose por veiculação hídrica, a porcentagem de soropositivos foi de $84,4 \%$ (Soroaglutinação Modificada - MAT). O parasita foi isolado em $37 \mathrm{de}$ 54 gatos testados e ao proceder a genotipagem 14 isolados foram caracterizados como tipo I e 23 como tipo III. A ausência do Tipo II nestes animais é consistente com os estudos prévios realizados em galinhas de vida livre (Tab. 1) e chama a atenção devido à ocorrência deste tipo em isolados de animais em outros países (DUBEY et al., 2004).

\section{Surtos de toxoplasmose em seres humanos}

A toxoplasmose é endêmica em grande parte do globo terrestre, estima-se que mais de dois bilhões 
de pessoas estejam infectadas cronicamente (SILVEIRA, 2002). Na maioria das vezes a toxoplasmose é assintomática porém a infecção durante a gestação pode levar ao abortamento, ao retardo motor e mental ou à perda da visão. O grau de infecção transplacentária e os efeitos danosos da multiplicação do T. gondii no feto dependem da época gestacional em que a infecção ocorreu. Lufte Remington (1992) estimam que em pacientes com síndrome da imunodeficiência adquirida (SIDA), a taxa de mortalidade para toxoplasmose varie entre 3 a $20 \%$.

Os surtos estão geralmente relacionados a pequenos grupos de indivíduos ou a famílias, o envolvimento de grandes grupos é infreqüente. Relatos de surtos são escassos, não em virtude da sua inexistência, mas devido ao fato dos sintomas serem, na maioria das vezes, ausentes ou brandos, tanto em humanos quanto em animais, o que acarreta dificuldades para a identificação clínica desta patologia e sua posterior confirmação laboratorial e notificação. Além disto a sintomatologia da toxoplasmose pode ser confundida com outras enfermidades. Desta forma, a grande maioria dos relatos está relacionada a cepas com grande virulência, que causam alterações clínicas agudas e características da infecção toxoplasmica, e à existência de uma vigilância constante em relação a esta doença. Avaliando-se surtos de toxoplasmose aguda em humanos demonstrou-se que as fontes de infecção e vias de transmissão variam nas diferentes populações humanas, devido à cultura e hábitos alimentares (BOWIE; KING; WERKER, 1997; TENTER; HECKEROTH; WEISS, 2000).

No Brasil o primeiro relato de surto de toxoplasmose na literatura médica, foi feito por Magaldi et al. (1967). Neste, de 81 pessoas que viviam em um seminário em Bragança Paulista -SP, 30 apresentaram toxoplasmose. Em virtude do pouco conhecimento sobre a epidemiologia da doença naquela época, os autores chegaram ao fim da investigação sem comprovações e conclusões à respeito das fontes de infecção ou das vias de transmissão.
Em outubro de 1977 um surto de toxoplasmose ocorreu entre os freqüentadores de um estábulo de montaria em Atlanta, Geórgia - EUA, 37 pessoas ficaram doentes, apresentaram sintomatologia característica ou soroconverteram na IFI. $T$. gondii foi isolado de tecidos de cinco de sete gatos e de quatro roedores capturados no local. Estudos epidemiológicos apontaram os gatos infectados como a fonte de infecção, sendo que os oocistos lançados ao solo foram transmitidos pela via aerógena ou pela contaminação das mãos e posterior ingestão (TEUTSH et al., 1979).

Sacks, Roberto e Brooks (1982) discorrem sobre um surto de toxoplasmose aguda ocorrido em outubro de 1978, ao norte da Califórnia - EUA; em um agrupamento familiar com 24 membros. Dez pessoas apresentaram evidências sorológicas da doença aguda pela IFI. Uma pessoa, caso índice, apresentou corioretinite, e as outras nove tiveram infecções assintomáticas. Todas as dez pessoas soropositivas tinham ingerido recentemente leite cru de cabra do rebanho da família.

Um surto de toxoplasmose envolvendo cinco membros de uma família libanesa, é tido como o primeiro reportado na Austrália. A via de infecção neste caso foi o quibe, um prato tradicional libanês no qual a carne crua é componente essencial e que não sofre nenhum tipo de processamento térmico para o consumo. Este surto foi descoberto eventualmente devido a um outro surto de hepatite A nesta mesma família (DE SILVA; MULCAHY; KAMATH, 1984).

No Canadá, um surto de toxoplasmose congênita em um povoado de Inuits, ao norte de Quebec, foi associado ao consumo freqüente da carne de caribu (Rungifer caribou). A soropositividade em mulheres grávidas do mesmo povoado foi associada ao consumo de carne de foca seca, fígado de foca e carne de caribu crua (MCDONALD et al., 1990).

Bonammeti et al. (1997) relatam, no dia 13 de setembro de 1993, a ocorrência de um surto em uma festa árabe realizada na cidade de Bandeirantes-PR. Nesta festa 17 pessoas se contaminaram pelo 
consumo de quibe cru de carne de carneiro. Estas apresentaram quadro clínico e perfil sorológico sugestivo com toxoplasmose aguda, a faixa etária variava entre seis e 57 anos. Na Austrália durante um coquetel em Queensland, um surto de toxoplasmose aguda e congênita também foi associado ao consumo de carne de canguru e de cordeiro, que não haviam sofrido o tratamento térmico adequado (ROBSON et al., 1995).

É importante considerar que os cistos de T. gondii também podem formar-se em vísceras e tecidos musculares. Relata-se a ocorrência de um surto de toxoplasmose aguda em humanos após o consumo de baço e fígado crus de javali e um segundo após o consumo de fígado cru de suíno doméstico; ambos aconteceram na Coréia, onde acredita-se que os fígados crus destes animais possuem um valor nutricional especial (CHOI; NAM; KWAK, 1997).

No Canadá, um surto envolvendo 100 pessoas com idades entre seis e 86 anos ocorreu em Greater Victoria, os indivíduos apresentaram sintomas sugestivos de toxoplasmose aguda ressaltando a retinite e a linfoadenopatia. Evidenciou-se, pela investigação dos dados, que a via de transmissão era a água do reservatório municipal fornecida à população. Vários fatores presentes no sistema de distribuição de água de Greater Victoria favoreceram o acontecimento deste surto, entre eles o acesso de felinos domésticos e selvagens ao reservatório, o uso de produtos químicos não efetivos na desinfecção primária e a precariedade do sistema de filtração da água (BOWIE; KING; WERKER, 1997).

Outro surto importante ocorreu no município de Santa Isabel do Ivaí localizado no noroeste do Estado do Paraná, Brasil. O município contava com uma população de aproximadamente 9000 habitantes e, de novembro de 2001 a janeiro de 2002, cerca de 600 pessoas procuraram o serviço de saúde com sintomas característicos de toxoplasmose, destas, 426 apresentaram sorologia compatível com toxoplasmose aguda (IgM+). Sete casos ocorreram em gestantes, sendo que uma apresentou aborto espontâneo e seis tiveram filhos infectados, um deles com anomalia congênita grave veio a óbito. Num primeiro exame oftalmológico, 176 casos foram avaliados, encontrando-se 14 (8\%) com alterações sugestivas da toxoplasmose ocular. O surto ocorreu em virtude da contaminação de um reservatório de água da cidade por oocistos de fezes de gatos jovens que habitavam o local, sendo que um dos filhotes apresentou sorologia positiva. A água era captada em poço artesiano e não passava por processos de coagulação ou filtração, sendo apenas clorada. Além dos indícios epidemiológicos, oocistos de T. gondii foram recuperados em uma caixa d'água de uma escola pública do município (FUNASA, 2002; SILVEIRA, 2002; DUBEY et al. 2004).

\section{Surtos de toxoplasmose em animais}

Hansen, Huldt e Thafvelin (1977) relataram, na Suécia, um surto fatal de toxoplasmose de origem congênita em leitões. Embora este seja o primeiro caso de manifestação de toxoplasmose em suínos na Suécia, foi baseado em infecção latente bem estabelecida na população animal da área envolvida. Os autores verificaram uma prevalência de 40,3\% dos animais em idade de terminação, com teste de Sabin-Feldman positivos.

Também na Alemanha, Bergmann, Heidrich e Kiupel (1980) descreveram a ocorrência de toxoplasmose aguda em rebanhos de coelhos domésticos, com idades variando entre dois e 18 meses, levando a perdas de 3 a $66 \%$. Foram verificadas lesões granulomatosas necrotizantes em vários órgãos como baço, fígado, rins e linfonodos de 49 animais. O baço dos animais apresentava grande quantidade de pseudocistos e cistos de $T$. gondii. Exames de microscopia dos órgãos, testes sorológicos e bioensaio em camundongos confirmaram a presença do T. gondii.

Um surto de toxoplasmose foi relatado, nos países baixos, em cangurus de face negra (Macropus fuliginosus melanops) cativos. Oito dos 25 cangurus adultos apresentavam anticorpos para $T$. gondii, em seis animais os dados sorológicos indicaram que a 
exposição havia sido recente, dois com títulos altos (> 16.384 - MAT) e cujas crias morreram com menos de sete meses de idade. Taquizoítos de $T$. gondii foram encontrados em vários órgãos de um filhote que veio a óbito com 82 dias de idade e numerosos cistos foram observados nos músculos esqueléticos de outro animal que faleceu com sete meses de vida. Os cangurus adultos apresentaram infecções subclínicas. O MAT foi mais sensível que a hemaglutinação indireta e a aglutinação em látex para a detecção de anticorpos contra o T. gondii no soro dos cangurus (DUBEY et al., 1988).

Um surto de toxoplasmose foi diagnosticado em 23 pássaros da raça mynahs (Acridotheres), importados do México para os Estados Unidos, resultando na morte de todas as aves durante a expedição. Os pássaros afetados mostraram-se inapetentes, prostrados e com penas eriçadas. A maioria das alterações incluíram manchas, hepatomegalia com múltiplos focos subcapsulares difusos, congestão renal e esplenomegalia. As alterações microscópicas foram de hepatite granulomatosa multifocal, pneumonites, inflamação difusa do baço, miocardite focal mononuclear e inflamação dos sacos aéreos. O T. gondii foi identificado por colorações especiais e microscopia eletrônica. A infecção pelo agente também foi diagnosticada no encarregado de cuidar dos animais (DHILON; THACKER; WINTERFIELD, 1995).

Frank (2001) discorre sobre um surto de toxoplasmose ocorrido em 1999 em uma grande fazenda de criação de vison (Mustela vision) em Wiscosin, EUA, na seqüência de um surto de cinomose canina; os principais sinais clínicos para as fêmeas gestantes incluíram a hiporexia, abortamentos e natimortalidade. Seis visons neonatos, 12 com três semanas de idade e duas fêmeas adultas foram encaminhados para diagnósticos laboratoriais. As lesões pós-morte se limitaram a estômago vazio (12 dos 12 filhotes) e palidez renal (quatro de 12 filhotes) para os animais com três semanas de idade. As principais lesões microscópicas incluíram pneumonia intersticial, encefalites, encefalomalácea e miocardites. A toxoplasmose foi diagnosticada por lesões microscópicas, pela distribuição destas lesões e pela detecção de taquizoítos por imunoistoquímica. Este é tido como o primeiro relato detalhado de surto de toxoplasmose em visons nos EUA.

\section{Prevenção}

O controle da eliminação de oocistos por gatos domésticos reduziria a transmissão da infecção para seres humanos e animais. O rompimento do ciclo natural, mantido por felinos selvagens é impraticável (FRENKEL, 1990).

Os gatos domésticos, como animais de companhia, podem ser mantidos no interior de residências com o mínimo de contato com o meio externo, com a alimentação controlada e a oferta de ração ou alimentos que sofreram tratamento térmico adequado (acima de $67^{\circ} \mathrm{C}$ ) (DUBEY, 1996; TENTER; HECKEROTH; WEISS, 2000). Em gatos com maior acesso ao meio externo pode ser colocada uma coleira com guizo, dessa forma é mais difícil a caça de roedores e pássaros (FRENKEL, 1990).

$\mathrm{Na}$ natureza um pássaro ou um roedor infectado pode contaminar apenas um ou alguns poucos carnívoros, já os animais de produção, cuja carne é utilizada para o consumo humano, podem infectar um maior número de pessoas (FRENKEL, 1990). Cistos de $T$. gondii podem ficar viáveis por dias em carne suína e ovina à temperatura de geladeira, entretanto tornam-se inviáveis ao congelamento $\left(-12^{\circ} \mathrm{C}\right)$ ou ao tratamento a temperaturas superiores a $67^{\circ} \mathrm{C}$ (DUBEY, 1996). O leite, principalmente o de cabra, deve ser ingerido somente após pasteurização ou fervura; as mãos devem ser lavadas após manusear carnes cruas, pois sabão, água, álcool e desinfetantes químicos inativarão bradizoítos e cistos teciduais remanescentes nas mãos após a manipulação destes alimentos (FRENKEL, 1990; DUBEY, 2000).

A prevenção da toxoplasmose torna-se mais importante em imunocomprometidos e mulheres 
grávidas (feto), visto que em tais condições a doença pode ser fatal (LUFT, 1989; DESMONTS; COUVREUR; THULLIEZ, 1990). A rotina de lavar as mãos antes de se alimentar e a de comer somente carnes que sofreram o tratamento térmico correto devem ser adotadas. Luvas devem ser utilizadas quando houver a necessidade de se trabalhar com terra ou areia, pois podem estar contaminadas com fezes de gato (KAPPERUD et al., 1996).

A posse de gatos, como animais de estimação por mulheres grávidas e pessoas imunocomprometidas, é um assunto que gera muitas dúvidas. Em um estudo de caso-controle realizado com mulheres grávidas em várias regiões da Europa, verificou-se que o contato com gatos não foi fator de risco para a infecção pelo T. gondii naqueles países (COOK; GILBERT; BUFFOLANO, 2000). A limpeza das caixas higiênicas dos felinos deve ser realizada diariamente, dando um destino adequado às fezes destes animais para que seja evitada a esporulação dos oocistos. Tal higienização não deve ser realizada por mulheres grávidas e indivíduos imunocomprometidos, evitando-se possíveis exposições a oocistos (FRENKEL, 1990). Não existem impedimentos para que pessoas imunocomprometidas e mulheres em gestação possuam gatos, desde que todas as medidas básicas de prevenção citadas sejam realizadas.

\section{Referências}

ARAÚJO, F.A.P.; SOUZA, W.J.S. Prevalência de toxoplasmose em suínos da região de Erechim (RS), detectados pela Imunofluorescência Indireta. In: CONGRESSO PANAMERICANO DE CIÊNCIAS VETERINÁRIAS, 15., 1996, Campo Grande. Anais... Campo Grande: Associação Pan-americana de Ciências Veterinárias e Sociedade Brasileira de Medicina Veterinária, 1996. p. 335.

BERGMANN, V.; HEIDRICH, R.; KIUPEL, H. Acute toxoplasmosis outbreak in rabbits flocks. Angewandte Parasitologie, Jena, v. 21, p. 1-6, 1980.

BONAMETTI, A.M.; PASSOS, J.N.; DA SILVA, E.M.K.; BORTOLIERO, A.L. Surto de toxoplasmose aguda transmitida através da ingestão de carne crua de gado ovino. Revista da Sociedade Brasileira de Medicina Tropical, São Paulo, v. 30, p. 21-25, 1997.

BOWIE, W.R.; KING, A.S.; WERKER, D.H.; ISAAC, Renton J. L.; BELL, A.; ENG, S. B.; MARION, S. A. Outbreak of toxoplasmosis associated with municipal drinking water. Lancet, London, v. 350, p. 173- 177, 1997.

CHOI, W.Y.; NAM, H.W.; KWAK, N.H.; HUH, W.; KIM, Y.R.; KANG, M. W.; CHO, S. Y.; DUBEY, J. P. Foodborn outbreaks of human toxoplasmosis. Journal of Infectious Diseases, Chicago, v. 175, p. 1280-1282, 1997.

COOK, A.J.; GILBERT, R.E.; BUFFOLANO, W.ZUFFEREY, J.; PETERSEN, E.; JENUM,P.A.; FOULON, W.; SEMPRINI, A. E.; DUNN, D. T. Sources of Toxoplasma infection in pregnant women: a European multicentre case-control study. British Medical Journal, Edinburgh, v. 15, p. 142$147,2000$.

DARDÉ, M. L. Biodiversity in Toxoplasma gondii. In: GROSS, U. Toxoplasma gondii. Berlin: Springer, 1996. p. 27-41.

DARDÉ, M.L.; BOUTEILLE, B.; PESTRE-ALEXANDRE, M. Isoenzymic characterization of seven strains of Toxoplasma gondii by isoeletrofocalisation on polyacrylamide gels. American Journal of Tropical Medicine and Hygiene, Mclean,v. 39, p. 551-558, 1988.

DEROUIN, F. Pathogeny and immunological control of toxoplasmosis. Brazilian Journal of Medical And Biological Research, Ribeirão Preto, v. 25, p. 1163-1169, 1992.

DE SILVA, L.M.; MULCAHY, D.L.; KAMATH, K.R. A family outbreak of toxoplasmosis: a serendipitous finding. J. Infect. v. 08, p. 163-167, 1984.

DESMONTS, G.; COUVREUR, J.; THULliEZ, P. Toxoplasmose congénitale: conq cas de transmission a l'enfant d'une infection maternelle antérieure a la grosesse. The Journal of Infection, London, v. 19, p. 1445-1449, 1990.

DHILON, A.S.; THACKER, H. L.; WINTERFIELD, R.W. Toxoplasmosis in mynahs. Avian Diseases, Kennett Square, v. 26, p. 445-449, 1995.

DUBEY, J.P. Toxoplasma, Hammondia, Besnoitia, sarcocystis, and other tissue cyst-forming coccidia of man and animals. In: KREIER, J. P. (Ed.). Parasitic protozoa gregarines, haemogregarines, coccidia, plasmodia and haemoproteids. New York: Academic Press, 1977. v.3, p.101-237.

DUBEY, J.P. Strategies to reduce transmission of Toxoplasma gondii to animals and humans. Veterinary Parasitology, Amsterdam, v.64, p.65-70, 1996. 
DUBEY, J.P. The scientific basis for prevention of Toxoplasma gondii infection: studies on tissue cyst survival, risk factors and hygiene measures. In: AMBROISE, Thomas P.; PETERSON, E. (Ed.). Congenital toxoplasmosis: scientific background, clinical management and control. Paris: Springer-Verlag, 2000. p. 271-275

DUBEY, J.P.; FRENKEL,J.K. Experimental Toxoplasma infection in mice with strains producing oocysts. Journal of Parasitology, Lawrence, v. 59, p.505-512, 1973

DUBEY, J.P.; MURREL, K.D.; FAYER, R. Persistence of encysted $T$. gondii in tissues of pigs fed oocysts. American Journal of Veterinary Research, Chicago, v. 45, p. 1941-1943, 1984.

DUBEY, J.P.; TOWLE, A. Toxoplasmosis in sheep. St. Albans: Commonwealth Institute of Parasitology, 1986.

DUBEY, J.P.; BEATIE, C.P. Toxoplasmosis of animals and man. Boca Raton: CRC Press, 1988.

DUBEY, J.P.; OTT-JOSLIN, J.; TORGERSON, R.W.; TOPPER, M. J.; SUNDBERG, J. P. Toxoplasmosis in blackfaced kangaroos (Macropus fuliginosus melanops). Veterinary Parasitology, Amsterdam, v. 30, p. 97-105, 1988.

DUBEY, J. P.; LEIGHTY, J. C.; BEAL, V. C.; ANDERSON, W. R.; ANDREWS, C. D.; THULLIEZ, P. National soroprevalence of Toxoplasma gondii in pigs. Journal of Parasitology, Lawrence, v. 77, p. 517-521, 1991.

DUBEY, J.P.; GRAHAM, D.H.; BLACKSTON, C.R.; LEHMANN, T.; GENNARI, S.M.; RAGOZO, A.M.A.; NISHI, S.M.; SHEN, S.K.; KWOK, O.C.H.; HILL, D.E.; THULLIEZ, P. Biological and genetic characterization of Toxoplasma gondii isolates from chickens (Gallus domesticus) from São Paulo, Brasil: unexpected findings. International Journal for Parasitology, Oxford, v. 32, p. 99-105, 2002.

DUBEY, J.P.; VENTURINI, M.C.; VENTURINI, L.; PISCOPO, M.; GRAHAM, D.H.; DAHL, E.; SREEKUMAR, C.; VIANNA, M.C.; LEHMANN, T. Isolation and genotyping of Toxoplasma gondii from free ranging chickens from Argentina. Journal of Parasitology, Lawrence, v. 89, p.1063-1064, 2003a.

DUBEY, J.P.; GRAHAM, D.H.; DAHL, E.; HILALI, M.; EL-GHAYSH, A. SREEKUMAR, C.; KWOK, O.C.H.; SHEN, S.K.; LEHMANN, T. Isolation and molecular characterization of Toxoplasma gondii from chickens and ducks from Egypt. Veterinary Parasitology, Amsterdam, v. 114, p. 85-89, 2003 b.

DUBEY, J.P.; GRAHAM, D.H.; DAHL, E.; SREEKUMAR, C.; LEHMANN, T.; DAVIS, M.F.; MORISHITA, T.Y. Toxoplasma gondii isolates from free ranging chickens from the United States. Journal of Parasitology, Lawrence, v. 89, p. 1060-1062, 2003c.
DUBEY, J.P.; GRAHAM, D.H.; SILVA, D.S.; LEHMANN, T.; BAHIA-OLIVEIRA, L.M.G. Toxoplasma gondii isolates of free ranging chickens from Rio de Janeiro, Brazil: mouse mortality, genotype, and oocyst shedding by cats. Journal of Parasitology, Lawrence, v. 89, p. 851-853, 2003d.

DUBEY, J.P.; NAVARRO, I.T.; GRAHAM, D.H,; DAHL, E.; FREIRE, R.L.; PRUDENCIO, L.B.; SREEKUMAR, C.; VIANNA, M.C.; LEHMANN, T. Characterization of Toxoplasma gondii isolates from free range chickens from Paraná Brazil. Veterinary Parasitology, Amsterdam, Article in press. Available online at http://www.sciencedirect.com, 2003e.

DUBEY, J. P.; NAVARRO, I. T.; SREEKUMAR, C.; DAHL, E.; FREIRE, R. L.; KAWABATA, H. H.; VIANNA, M. C. B.; KWOK, O. C. H.; SHEN, S. K.; THULLIEZ, P.; LEHMANN, T. Toxoplasma gondii infections in cats from Paraná, Brazil: seroprevalence, tissue distribution, and biologic and genetic characterization of isolates. Journal of Parasitology, Lawrence, v.90, n.4, p.721-726,2004.

FERREIRA, A.M.; VITOR, R.W.A.; CARNEIRO, A.C.A.V.; MELO,M.N. Caracterização molecular de cepas de Toxoplasma gondii isoladas no Brasil. In: CONGRESSO BRASILEIRO DE PARASITOLOGIA, 18., 2003, Rio de Janeiro. Anais... Rio de Janeiro: Colégio Brasileiro de Parasitologia, 2003.p.30.

FRANK, R.K. An outbreak of toxoplasmosis in farmed mink (Mustela vision). Journal of Veterinary Diagnostic Investigation, Columbia, v. 13, p. 245-249, 2001.

FRENKEL, J.K. Toxoplasmosis in human beings. Journal of The American Veterinary Medical Association, Schaumburg, v. 196, n.2, p. 240-248, 1990.

FUENTES, I.; RUBIO, J.M.; RAMIREZ, C.; ALVAR, J. Genotipic characterization of Toxoplasma gondii strains associated with human toxoplasmosis in spain: direct analisis from clinical samples. Journal of Clinical Microbiology, Washington, v. 39, p. 1566-1570, 2001.

FUNASA - Boletim Eletrônico EPIDEMIOLÓGICO - P. 01-03, 20/08/02.

GRIGG, M.E.; GANATRA, D.H.; BOOTHROOYD, J.C.; MARGOLIS, T.P. Unusual abundance of atypical strains associated with human ocular toxoplasmosis. Journal of Infectious Diseases, Chicago, v. 184, p. 633-639, 2001.

GUERINA, N.G.; HSU, H.W.; MEISSNER, H.C.; MAGUIRE, J.H.; LYNFIELD, R.; STECHENBERG, B.; ABROMS, I.; PASTERNACK, M.S.; HOFF, R.; EATON, R. B.; GRADY, G. F.; CHEESEMAN, S. H.; MCINTOSH, K.; MEDEARIS, D. N.; ROBB, R.; WEIBLEN, B. J. Neonatal serologic screening and early treatment for congenital Toxoplasma gondii infection. New England Journal of Medicine, v. 330, p. 1858-1863, 1994. 
HANSEN, H.J.; HULDT, G.; THAFVELIN, B. On porcine toxoplasmosis in Sweden. Nord. Veterinaermedicin. v. 29, p. 381-385, 1977.

HOWE, D.K.; SIBLEY, L.D. Toxoplasma gondii comprises three clonal linages: correlation of parasite genotype with human disease. Journal of Infectious Diseases, Chicago, v. 172,p. 1561-1566, 1995.

HOWE, D.K.; HONORÉ, S.; DEROUIN, F.; SIBLEY, L.D. Determination of genotypes of Toxoplasma gondii strains isolated from patients with toxoplasmosis. Journal of Clinical Microbiology, Washington, v. 36, p. 1411-1414, 1997.

JACOBS, L.; LUNDE, F. The interrelation of toxoplasmosis in swine, cattle, dogs and man. Public Health Reports, Washington, v. 72, n.10, p. 872-882, 1957.

KAPPERUD, G.; JENUM, P.A.; STRAY-PEDERSEN, B.; MELBY,K.K.; ESKILD, A.; ENG, J. Risk factors for Toxoplasma gondii infection in pregnancy: results of a prospective casecontrol study in Norway. American Journal of Epidemiology, Baltimore, v. 144, p. 405-412, 1996.

KOSKI, V.H. Evaluation of ELISA for the detection of Toxoplasma antibodies in swine sera. Acta Veterinaria Scandinavica, Copenhagen, v. 31, p. 413-422, 1990.

LUFT, B.J. Toxoplasma gondii. In: WALZER, P. D.; GENTA, R.M. (Ed.). Parasitic infections in the compromised hosts. New York: Marcel Dekke, 1989. p. 179-279.

LUFT, B.J.; REMINGTON, J.S. Toxoplasmic encephalitis in AIDS. Clinical Infectious Diseases, Chicago, v. 15, p. 211-222, 1992.

MAGALDI, C.; ELKIS, H.; PATTOLI, D.; QUIRÓZ, J.C.; COSCINA, A.L.; FERREIRA, J.M. Surto de toxoplasmose em seminário de Bragança Paulista (Estado de São Paulo). Aspectos clínicos, sorológicos e epidemiológicos. Revista de Saúde Pública, São Paulo, v. 1, n. 2, p. 141-171, 1967.

MCDONALD, J.C.; GYORKOS, T.W.; ALBERTON, B.; MACLEAN, J.D.; RICHER, G.; JURANEK, D. An outbreak of toxoplasmosis in pregnant women in northern Quebec. Journal of Infectious Diseases, Chicago, v. 161, p. 769-774, 1990.

MITSUKA-BREGANÓ, R. ; SILVA, A. C. B. ; BREGANÓ, J. W. ; ALFIERI, A. ; JANKEVICIUS, J. V. ; VIDOTTO, O. . Toxoplasma gondii: II. Caracterização antigênica de taquizoítos de oito amostras. Brazilian Journal of Veterinary Research And Animal Science, São Paulo, v. 35, n. 3, p. 110-114, 1998.

MONDRAGON, R.; HOWE, D.K.; DUBEY, J.P.; SIBLEY, L.D. Genotypic analysis of Toxoplasma gondii isolates from pigs. Journal of Parasitology, Lawrence, v. 84, p. 639-641, 1998.
MONTOYA, F.M.; RAMIREZ, E.L.; LOAIZA, H.A.; HENAO, C.J.; MURILLO, G.G. Prevalencia de anticuerpos para Toxoplasma gondii en bovinos y porcinos. Boletin de la Oficina Sanitaria Panamericana, Washington, v.91, n.5, p. 219-225, 1981.

NAVARRO, I.T.; VIDOTTO, O.; GIRALDI, N.; FREIRE, R.L. Toxoplasma gondii: Isolamento a partir de carne e cérebro de suínos comercializados na região de Londrina, Pr. Semina: Ciência Agrarias, Londrina, v. 13, p. 15-18, 1992.

PORTO, W.J.N.; RIBEIRO, T.C.E.S.; LEITE, A.S.; ALVES, L.C.; BARBOSA, C.L.; MOTA, R.A.; PEREIRA, G.C.; CARVALHO JÚNIOR, G.M. Frequência de suínos sororeagentes para Toxoplasma gondii na região metropolitana do Recife. In: CONGRESSO BRASILEIRO DE PARASITOLOGIA VETERINÁRIA, 11., Salvador, 1999. Anais... Salvador: Colégio Brasileiro de Parasitologia Veterinária, 1999.p. 219.

ROBSON, J.M.B.; WOOD, R.N.; SULLIVAN, J.J.; NICOLAIDES, N.J.; LEWIS, B.R. A probable foodborne outbreak of toxoplasmosis. Communicable Diseases Intelligence, Canberra, v. 19, p. 517-522, 1995.

RUIZ, A.; FRENKEL, J.K. Intermediate and transport hosts of Toxoplasma gondii in Costa Rica. American Journal of Tropical Medicine and Hygiene, Mclean, v. 29, p. 1161-1166, 1980.

SACKS, J.J.; ROBERTO, R.R.; BROOKS, N.F. Toxoplasmosis infection associated with raw goat's milk. J. of the Amer. Med. Associat. v. 248, p. 1728-1732, 1982.

SILVEIRA, Cláudio Alberto Magalhães. Toxoplasmose: Dúvidas e Controvérsias. Erechim: Edipafes, 2002. 152p.

SUAREZ-ARANDA, F.; GALISTEO JR, A.J.; HIRAMOTO, R.M.; CARDOSO, R.P.A.; MEIRELES, L.R.; MIGUEL, O.; ANDRADE JR, H.F. The prevalence and avidity of Toxoplasma gondii IgG antibodies in pigs from Brazil and Peru. Veterinary Parasitology, Amsterdam, v. 91, p. 23-32, 2000.

TENTER, A. M., HECKEROTH, A. R.; WEISS, L.M. Toxoplasma gondii: from animals to humans. International Journal For Parasitology, Oxford, v. 30, p. 1217-1258, 2000.

TEUTSCH, S.M.; JURANEK, D.D.; SULZER, A.; DUBEY, J.P.; SUKES, R.K. Epidemic toxoplasmosis associated with infected cats. New England Journal of Medicine, Waltham, v. 300, p. 695-699, 1979.

TSUTSUI, V.S. Soroepidemiologia e fatores associados à transmissão do Toxoplasma gondii em suínos do norte do Paraná. Trabalho de Conclusão de Curso (Graduação) - Universidade Estadual de Londrina. Londrina, 2000.

VIDOTTO, O.; NAVARRO, I.T.; GIRALDI, N.; MITSUKA, R.; FREIRE, R.L. Estudos epidemiológicos da toxoplasmose em suínos da região de Londrina - PR. Semina: Ciências Agrarias, Londrina, v. 11, n.1, p. 53-59, 1990. 